\title{
Plant-derived pectin nanocoatings to prevent inflammatory cellular response of osteoblasts following Porphyromonas gingivalis infection
}

This article was published in the following Dove Press journal:

International Journal of Nanomedicine

12 January 2017

Number of times this article has been viewed

\author{
Anna Meresta' \\ Justyna Folkert' \\ Timo Gaber ${ }^{2}$ \\ Korneliusz Miksch' \\ Frank Buttgereit ${ }^{2}$ \\ Jacqueline Detert ${ }^{2}$ \\ Nicole Pischon ${ }^{3, *}$ \\ Katarzyna Gurzawska $3,4, *$ \\ 'Environmental Biotechnology \\ Department, Faculty of Power and \\ Environmental, Silesian University \\ of Technology, Gliwice, Poland; \\ ${ }^{2}$ Department of Rheumatology and \\ Clinical Immunology, ${ }^{3}$ Department of \\ Periodontology, Charité University \\ Medicine, Berlin, Germany; ${ }^{4}$ Oral \\ Surgery Department, The School of \\ Dentistry, University of Birmingham, \\ Birmingham, UK
}

*These authors contributed equally to this work
Background: Bioengineered plant-derived Rhamnogalacturonan-Is (RG-Is) from pectins are potential candidates for surface nanocoating of medical devices. It has recently been reported that RG-I nanocoatings may prevent bacterial infection and improve the biocompatibility of implants. The aim of the study was to evaluate in vitro impact of bioengineered RG-I nanocoatings on osteogenic capacity and proinflammatory cytokine response of murine osteoblasts following Porphyromonas gingivalis infection.

Methods: Murine MC3T3-E1 osteoblasts and isolated primary calvarial osteoblasts from C57BL/6J (B6J osteoblasts) mice were infected with $P$. gingivalis and incubated on tissue culture polystyrene plates with or without nanocoatings of unmodified RG-Is isolated from potato pulps (PU) or dearabinanated RG-Is (PA). To investigate a behavior of infected osteoblasts cultured on RG-Is cell morphology, proliferation, metabolic activity, mineralization and osteogenic and pro-inflammatory gene expression were examined.

Results: Following $P$. gingivalis infection, PA, but not PU, significantly promoted MC3T3-E1 and BJ6 osteoblasts proliferation, metabolic activity, and calcium deposition. Moreover, $I l-1 b$, Il-6, TNF- $\alpha$, and Rankl gene expressions were downregulated in cells cultured on PU and to a higher extent on PA as compared to the corresponding control, whereas Runx, Alpl, Collal, and Bglap gene expressions were upregulated vice versa.

Conclusion: Our data clearly showed that pectin RG-Is nanocoating with high content of galactan $(\mathrm{PA})$ reduces the osteoblastic response to $P$. gingivalis infection in vitro and may, therefore, reduce a risk of inflammation especially in immunocompromised patients with rheumatoid or periodontal disorders.

Keywords: nanocoatings, Rhamnogalacturonan-I, Porphyromonas gingivalis, osteoblasts, inflammation

\section{Introduction}

The most prevalent chronic inflammatory diseases of humans are complex disorders of multifactorial etiology influenced by genes, environment, and their interactions. Periodontitis (PD) and rheumatoid arthritis (RA) are two chronic inflammatory diseases associated with significant morbidity and mortality, and studies have recently shown that they may have a bidirectional association. ${ }^{1,2}$ RA and PD have common risk factors and share pathogenic mechanisms related to Porphyromonas gingivalis. ${ }^{3-5}$ In PD and RA patients the degradation of connective and mineralized tissue is observed. ${ }^{6}$ Increased alveolar bone volume loss has recently been shown to be associated with the occurrence of a Gram-negative, black-pigmented, strict anaerobic bacterium $P$. gingivalis. ${ }^{7-9}$ The pathogenic effect might be induced indirectly through multiple virulence factors,
Correspondence: Katarzyna Gurzawska Oral Surgery Department,

The School of Dentistry, University of Birmingham, St Chad's Queensway, B4 6NN Birmingham, UK

Tel +44 I2I 4665496

Fax +44 I 2 I 4665493

Email k.a.gurzawska@bham.ac.uk 
such as lipopolysaccharides (LPSs), fimbriae, and proteases, as well as through direct interaction with the host's soft and hard tissues. ${ }^{10}$ Therefore, in medically compromised patients where bone metabolism is affected, improvement of bone regeneration is needed.

Recently, it was reported that plant-derived polysaccharides, mainly Rhamnogalacturonan-I (RG-I) pectins, have potential to improve bone regeneration, ${ }^{11-13}$ prevent inflammation, ${ }^{14,15}$ and act as a delivery mechanism for therapeutic agents. ${ }^{15} \mathrm{RG}-\mathrm{I}$ is the first molecule derived from plants that has been introduced and tested as a potential nanocoating to be applied to biomaterial surfaces, for example, titanium, to improve bone healing and osseointegration. ${ }^{11,16}$ RG-I is a subunit of pectin composed of a backbone of alternating rhamnose (Rha) and galacturonic acid (GalA) residues, whereas arabinian and (arabino-)galactan side chains are present on the rhamnosyl residues. The structure of RG-I can be enzymatically modified, which results in different physicochemical properties, such as total charge, side-chain branching, and molecular weight. ${ }^{11}$ Well-established methods for controlling RG-Is' structure modification open new possibilities for using these plantderived molecules as biomaterials to improve the biocompatibility of medical devices. ${ }^{14,17}$

Pectins are analogs to human carbohydrates from extracellular matrix (ECM), providing bio-specific cell adhesion and initiating bone cells activities. ${ }^{17}$ The osteoblast activity is essential for development, maturation, and repair of the bone. Osteoblastic cells differentiate from mesenchymal stem cells. Osteoblasts are adherent and anchorage-dependent cells, thus the attachment to ECM proteins, such as fibronectin, is required for cell differentiation. Mature osteoblasts are capable of producing ECM through osteoid and mineralizing with $\mathrm{Ca}^{2+} .{ }^{11,17}$

The hypothesis is that pectin RG-I with a high amount of galactose (Gal RG-I) enhances osteoblasts spreading and growth on the surface of coated biomaterials, therefore stimulates bone healing. Our previous in vitro studies showed that pectin nanocoating with RG-Is having high content of galactose and low content of arabinose increased mineralized matrix formation of osteoblast-like cells (SaOS-2). ${ }^{16,18,19}$

RG-Is anti-inflammatory properties reported by Nagel et $\mathrm{al}^{15}$ and Bussy et $\mathrm{al}^{14}$ may prevent delay in bone regeneration connected with bacterial infection. The RG-Is promote B-cell proliferation and complement fixing activity, in addition to their stimulation of proliferation of bone marrow cells through the immune system. ${ }^{20}$ In addition its interaction with $\beta$-integrins prevents neutrophil adhesion to fibronectin, which represents a key step of the inflammatory response. $^{21,22}$
Additionally, pectins are not degradable by the human body, ${ }^{11,12}$ relatively inexpensive, and easy to obtain in comparison to proteins, which are most commonly used for improvement of bone regeneration. ${ }^{23}$

As it is generally accepted that osteoblast activity is important for bone regeneration, the aim of this study was to evaluate the effect of RG-I nanocoating on in vitro mice osteoblast proliferation, metabolic activity, mineralization, and modulation of proinflammatory cytokine response stimulated by $P$. gingivalis infection.

\section{Experimental Isolation, modification, and nanocoating of RG-I}

RG-I from potato pulps (potato unmodified RG-I [PU]) was isolated according to the procedure as previously published. ${ }^{16}$ Briefly, the enzymatic modification of potato RG-I was done using polygalacturonase-I (PG-I, Novozymes, Copenhagen, Denmark) and polygalacturonase-III (PG-III, Novozymes) together with pectin methylesterase (PME, Novozymes). The arabinose side chains of potato RG-I were removed with $\alpha$-L-arabinofuranosidase and endo-arabinanase; galactose side chains were removed with $\beta$-galactosidase and endo$\beta$-1,4-galactanase. The chemical properties, monosaccharide composition, and linkage analysis of PU (unmodified) and potato dearabinanated RG-I (PA) (modified) have been presented in our previous work. ${ }^{16}$ Adherently, PU and PA RG-Is $(128 \mu \mathrm{g} / \mathrm{mL})$ were coated on the surface of 6 -well, 24-well, and 96-well tissue culture polystyrene (TCPS) plates (Techno Plastic Product, Trasadingen, Switzerland). The reaction was carried out at room temperature overnight in sterile conditions on the shaker (IKA-Werke GmbH \& Co. KG, Staufen, Germany) with $100 \mathrm{rpm}$, and then the plates were extensively rinsed in sterile water and dried in a laminar flow hood before in vitro experiments. The detection of PU and PA RG-Is nanocoating was performed using enzyme-linked immunosorbent assay (ELISA) before and after in vitro tests following a procedure presented in our previous study. ${ }^{16}$

\section{In vitro studies}

The TCPS with PU and PA nanocoatings were tested surfaces and TCPS without the RG-Is were control surfaces. Mice osteoblast-like cells MC3T3 and primary osteoblast isolated from calvariae of C57BL/6J mice were cultured on tested and control surfaces and infected with $P$. gingivalis to examine their inflammatory response. The primary osteoblasts were extracted from two mice, and all in vitro experiments were repeated twice. The in vitro assays such as proliferation, 
cell metabolic activity, mineralization, and gene expression analysis were repeated six times each $(n=6)$.

\section{Cell culture}

MC3T3-E1 osteoblast-like cells were grown in a cell culture medium consisting of minimum essential medium (MEM) (Gibco, Darmstadt, Germany), 18\% fetal bovine serum (FBS) (Biochrom, Berlin, Germany), antibiotic (100 mg/L streptomycin and $100 \mathrm{U} / \mathrm{mL}$ penicillin) (Biochrom), and $10 \mathrm{~mL} / \mathrm{L}$ L-glutamine (Biochrom) and then incubated at $37^{\circ} \mathrm{C}$ with $5 \% \mathrm{CO}_{2}$ (Heraeus, Hanau, Germany). Primary cells (B6J osteoblasts) were isolated from calvariae of two C57BL/6J mice as described previously ${ }^{24}$ and grown in a cell culture medium consisting of MEM (Gibco), 10\% FBS (Biochrom), antibiotic $(100 \mathrm{mg} / \mathrm{L}$ streptomycin and $100 \mathrm{U} / \mathrm{mL}$ penicillin) (Biochrom), and $10 \mathrm{~mL} / \mathrm{L}$ non-essential amino acids (Biochrom) and then incubated at $37^{\circ} \mathrm{C}$ with $5 \% \mathrm{CO}_{2}$. The cell morphology was observed and registered before and after infection with $P$. gingivalis by light microscopy (Leitz, Labovert, Germany). For proliferation assays, $1 \times 10^{5}$ cells/ $\mathrm{mL}$ were seeded on 96-well TCPS and cultured for 12, 24, 48 , and $72 \mathrm{~h}$. For real-time polymerase chain reaction (PCR), $5 \times 10^{4}$ cells $/ \mathrm{mL}$ were seeded on 6 -well TCPS and cultured for $3,7,14$, and 21 days. For cell metabolic activity and mineralization, $2 \times 10^{4}$ cells $/ \mathrm{mL}$ were seeded on 24 -well TCPS and cultured for $3,7,14$, and 21 days. For mineralization assay, the culture medium in all wells was replaced after $24 \mathrm{~h}$ with the mineralization medium additionally consisting of $50 \mu \mathrm{L} / \mathrm{mL}$ ascorbic acid (Sigma-Aldrich, Seelze, Germany) and $10 \mathrm{mM}$ glycerol 2-phosphate disodium salt hydrate (Sigma-Aldrich). The mineralization medium was changed every third day.

\section{P. gingivalis cultivation}

P. gingivalis strain ATCC 33277 (American Type Culture Collection, Manassas, VA, USA) examined by a microbiological test kit ID 32A (API BioMérieux, Marcy l'Etoile, France) was grown anaerobically at $37^{\circ} \mathrm{C}$ on Columbia agar (Sifin Diagnostics GmbH, Berlin, Germany) containing 5\% sheep blood (Acila Sarl, Weiterstadt, Germany), 0.1\% vitamin K (Sigma-Aldrich, Seelze, Germany), and 0.25\% hemin (Fisher Scientific GmbH, Schwerte, Germany) for 3-5 days.

\section{P. gingivalis infection assay}

$P$. gingivalis strain was resuspended in the Alpha MEM (Gibco) containing no antibiotics. The number of bacteria was determined using an UV-visible spectrophotometer (Shimadzu Co., Kyoto, Japan) at an optical density of $520 \mathrm{~nm}$, based on a standard curve established by colony formation on bacterial plates. A multiplicity of infection of 100 was used to infect B6J and MC3T3-E1 osteoblasts. Briefly, confluent osteoblast monolayers were infected with $P$. gingivalis and incubated for $2 \mathrm{~h}$ (at $37^{\circ} \mathrm{C}$ in $5 \% \mathrm{CO}_{2}$ ). After incubation of bacteria with the osteoblast cells, the supernatant was replaced with a fresh medium containing $0.5 \mathrm{mg} / \mathrm{mL}$ gentamicin (Biochrom) and $0.1 \mathrm{mg} / \mathrm{mL}$ metronidazole (Sigma-Aldrich, Munich, Germany) for $1 \mathrm{~h}$ in order to eliminate remaining extracellular (EC) bacteria. After $1 \mathrm{~h}$, the B6J and MC3T3-E1 osteoblast cultures were washed twice with sterile phosphate buffered saline (PBS), and fresh MEM containing FBS and antibiotics were applied to each well. The infected cells were incubated under standard conditions (at $37^{\circ} \mathrm{C}$ in $5 \% \mathrm{CO}_{2}$ ) for in vitro experiments.

\section{Proliferation}

Cell proliferation was performed using bromodeoxyuridine (BrdU). The BrdU incorporated into new synthesized DNA was quantified after 12, 24, 48, and 72 h. Briefly, BrdU (Roche Diagnostics GmbH, Mannheim, Germany) was applied to the culture medium and incubated $\left(37^{\circ} \mathrm{C}, 5 \% \mathrm{CO}_{2}\right)$. After $2 \mathrm{~h}$, the medium was discarded and the cells were fixed in $70 \%$ ethanol for $30 \mathrm{~min}$. Ethanol was removed by drying. The fixed cells were incubated with an anti-BrdU antibody for $2 \mathrm{~h}$. The absorbance from each well was measured using the Microplate Reader 500 at $450 \mathrm{~nm}$. The wells without cells containing culture medium, BrdU, and anti-BrdU antibody served as blank control for unspecific binding to the wells. The wells with cells incubated with anti-BrdU antibody for unspecific binding to the cells were used as a background control. The wells without cells containing only the culture medium were used as a blank; wells with cells incubated with the anti-BrdU antibody for unspecific binding were used as a background and were subtracted from all measurements.

\section{Cell metabolic activity and mineralization assay}

Cell metabolic activity using water-soluble tetrazolium salt (WST-1) and mineralization with Alizarin Red-S (AR-S) assays were performed at the same time in parallel. For assessing the cell metabolic activity assay, the culture medium was removed after 3, 7, 14, 21 days, and the experimental medium containing 10\% $(100 \mu \mathrm{L}) \mathrm{WST}-1$ reagent (Roche, Hvidovre, Denmark) was added $(250 \mu \mathrm{L} /$ well). The plates were incubated at $37^{\circ} \mathrm{C}$ with $5 \% \mathrm{CO}_{2}$ for $1 \mathrm{~h}$ and $100 \mu \mathrm{L} /$ well was transferred to a 96-well ELISA plate (Nunc, Roskilde, Denmark). The plate was shaken before readings, at 450 and $650 \mathrm{~nm}$ (baseline correction), by a Microplate Reader 500. Wells containing the WST-1 medium without cells were used as a background and were 
subtracted from all measurements. For the mineralization, the cells were fixed in ice-cold $70 \%$ ethanol $(1 \mathrm{~mL} /$ well $)$ for $1 \mathrm{~h}$ at $4^{\circ} \mathrm{C}$. The wells were washed with $1 \mathrm{~mL}$ distilled water, and cell mineral matrix was stained with $500 \mu \mathrm{L}, 40 \mathrm{mM}$ AR-S (Sigma-Aldrich), at $\mathrm{pH} 4.2$ for $10 \mathrm{~min}$ at room temperature with shaking rotation of $100 \mathrm{rpm}$. The wells were washed three times with $1 \mathrm{~mL}$ distilled water and finally washed with $1 \mathrm{~mL}$ PBS with calcium and magnesium (PBS+, Biochrom) for $15 \mathrm{~min}$ at room temperature with shaking rotation of 100 rpm to reduce nonspecific AR-S staining. Cell mineral matrix was distained in $500 \mu \mathrm{L} \mathrm{10 \%} \mathrm{cetylpyridinium} \mathrm{chloride} \mathrm{(CPC)}$ (Sigma-Aldrich), for $15 \mathrm{~min}$ at room temperature with rotation of $100 \mathrm{rpm}$. Standard dilution and AR-S-extracts were applied $(200 \mu \mathrm{L} /$ well $)$ into a 96-well ELISA plate, and AR-S concentrations were determined at $562 \mathrm{~nm}$ by a Microplate Reader 500. Measurements were performed using $650 \mathrm{~nm}$ as a reference. Additionally, standards were applied, $1.0 \mathrm{mM}$ AR-S (Sigma-Aldrich) and 10\% CPC (Sigma-Aldrich), to calculate the content of calcium in each well using analytical curve.

\section{Gene expression and real-time PCR}

The RNA isolation was carried out after 3, 7, 14, and 21 days using the RNeasy mini kit (Qiagen, Hilden, Germany) according to the procedure published previously. ${ }^{18}$ The reverse transcription (RT) PCR was determined using onestep high-capacity cDNA RT kit (Applied Biosystem, Foster City, CA, USA). The level of gene expression was calculated with comparative $\mathrm{C}_{\mathrm{t}}$ method $\left(\Delta \Delta \mathrm{C}_{\mathrm{t}}\right)$. Results of actin beta $(A c t b)$ expression were used as a $\mathrm{C}_{\mathrm{t} \text { reference }}$ for each of sample, and results of investigated genes obtained for independent additional sample (RNA isolated from 3 days osteoblasts) were used as $\Delta \mathrm{C}_{\mathrm{t} \text { calibrator sample }}$.

SsoAdvanced ${ }^{\mathrm{TM}}$ Universal SYBR Green Supermix (BioRad, Munich, Germany) was used for expression of target genes (Table 1): osteoblast transcription factor (Runx2), alkaline phosphate $(A l p l)$, osteocalcin (Bglap), collagen type 1
(Collal), receptor activator for nuclear factor kappa B ligand (Rankl), tumor necrosis factor-alpha $(T N F-\alpha)$, interleukin-1 beta $(\mathrm{Il}-1 \mathrm{~b})$, interleukin-6 ( $\mathrm{Il}-6)$, and actin beta (Actb) as endogenous control genes. Manually prepared cDNA of 2 and $8 \mu \mathrm{L}$ reaction mix was pipetted to each well of 96-well plate (Bio-Rad), according to manufacturer's instructions, and analysis was performed with the CFX96 real-time PCR detection system (Bio-Rad).

\section{Statistical analyses}

Descriptive statistics were used and mean values were calculated. Results of the in vitro experiments were analyzed using one-way analysis of variance tests and Bonferroni corrections for multiple comparisons to controls using Statistical Package for the Social Sciences (SPSS) 11.5 software. A significance level, a $P$-value of $5 \%$, was used throughout.

\section{Results}

\section{In vitro studies}

The results of all in vitro assays, proliferation, cell metabolic activity, mineralization, and gene expression were higher in MC3T3-E1 cell culture compared with primary B6J osteoblast cells analyzed at different time points. For B6J osteoblast cells, the results were presented only for one mouse, as no significant difference was found between mice.

\section{Morphology of osteoblast cells}

The morphology of B6J osteoblast cells after $P$. gingivalis infection is presented in Figure 1. In contact with PU, PA, and TCPS, infected B6J osteoblasts were elongated, but less aggregated on TCPS. The bacterial infection caused less spreading of the cells on the PU- and PA-coated surfaces compared to TCPS control.

\section{Proliferation}

The difference in proliferation rate over time is observed between cell line and primary osteoblasts after $P$. gingivalis

Table I Characteristic of genes used for real-time PCR

\begin{tabular}{|c|c|c|c|c|c|c|}
\hline Gene name & $\begin{array}{l}\text { Gene } \\
\text { symbol }\end{array}$ & $\begin{array}{l}\text { Gene } \\
\text { ID }\end{array}$ & Unique assay ID & $\begin{array}{l}\text { Chromosome } \\
\text { location }\end{array}$ & $\begin{array}{l}\text { Amplicon } \\
\text { length }\end{array}$ & Assay design \\
\hline Actin beta & Actb & II46I & qMmuCED0027505 & 5:142904472-142904610 & 109 & Exonic \\
\hline Runt-related transcription factor 2 & Runx2 & 12393 & qMmuCID0005205 & $17: 44658643-447 \mid 7289$ & 118 & Intron spanning \\
\hline Collagen, type I, alpha I & Collal & 12842 & qMmuCED0044222 & II:94950400-949505I5 & 86 & Exonic \\
\hline Alkaline phosphatase & Alpl & 11647 & qMmuCID0006482 & $4: 137755656-\mid 37758687$ & 180 & Intron spanning \\
\hline Bone gamma carboxyglutamate protein & Bglap & 12096 & qMmuCED004I364 & $3: 88384 \mid 92-88384433$ & 67 & Exonic \\
\hline Tumor necrosis factor (ligand) superfamily, member II & Tnfsfl I & 21943 & qMmuCID0026078 & |4:78284239-782999|6 & 194 & Intron spanning \\
\hline Tumor necrosis factor & Tnf & 21926 & qMmuCED0004l4I & 17:3520|7|7-3520|865 & 119 & Exonic \\
\hline Interleukin-I beta & $I I-I b$ & 16176 & qMmuCED0045755 & $2: 129367975-129368089$ & 85 & Exonic \\
\hline Interleukin-6 & $11-6$ & 16193 & qMmuCED0045760 & $5: 30013377-30013476$ & 70 & Exonic \\
\hline
\end{tabular}

Abbreviation: PCR, polymerase chain reaction. 

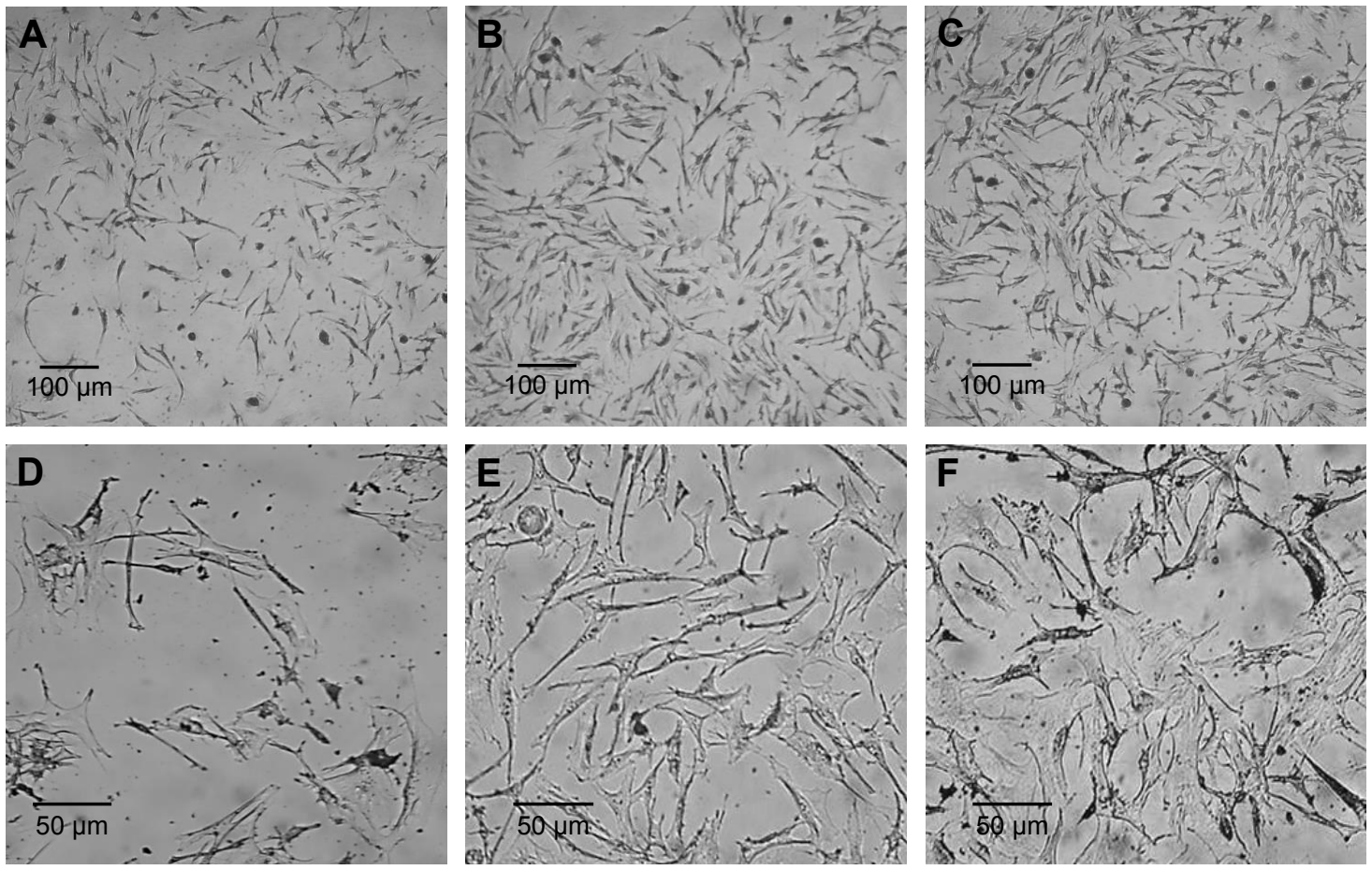

Figure I Representative images of B6J osteoblasts morphology after Porphyromonas gingivalis infection (A, D) on control surfaces, (B, E) on the surface coated with potato

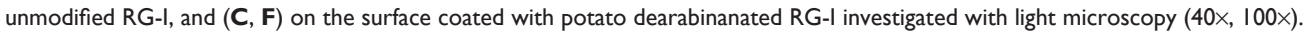

Abbreviation: RG-I, Rhamnogalacturonan-I.

infection (Figure 2). The proliferation increased over time, where the lowest results were observed after $12 \mathrm{~h}$ and the highest after $72 \mathrm{~h}$ in both MC3T3-E1 and B6J osteoblast cell cultures. The proliferation of B6J osteoblast cells at the PA-coated surface was significantly higher $(P<0.01)$ after 12 and $72 \mathrm{~h}$ compared to control. After 24 and $48 \mathrm{~h}$, no significant difference between PA and control was found.
The proliferation of MC3T3-E1 at the PA-coated surface was significantly higher $(P<0.05)$ after $24 \mathrm{~h}$ compared to control, but no difference was found after 12, 48, and $72 \mathrm{~h}$.

\section{Cell metabolic activity}

The results of cell metabolic activity assay (Figure 3) showed that after $P$. gingivalis infection, the cellular metabolic
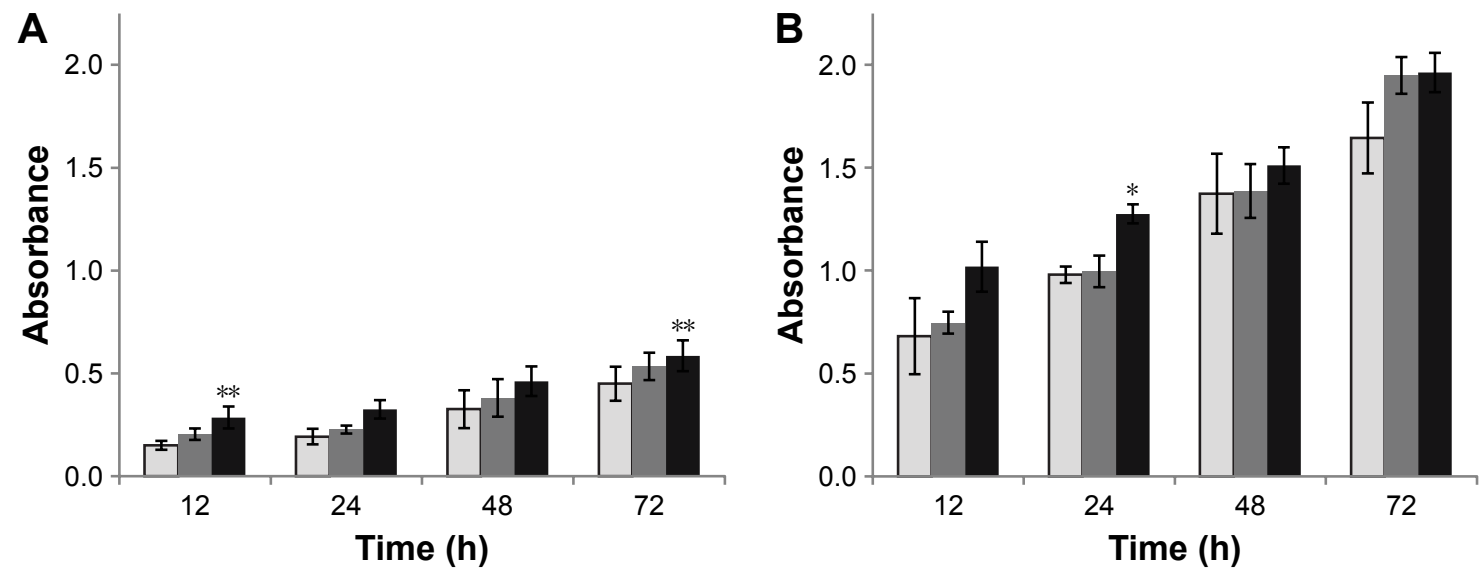

$\square C \square P U \square P A$

Figure 2 Proliferation activity of B6J (A) and MC3T3-EI osteoblast cells (B) after Porphyromonas gingivalis infection measured by the colorimetric method using bromodeoxyuridine after $12,24,48$, and $72 \mathrm{~h}$ (mean \pm SEM, $\mathrm{n}=6$ ).

Notes: The results represent absorbance values measured at $450 \mathrm{~nm}$ against the background control wells using $650 \mathrm{~nm}$ as a reference. ANOVA tests and Bonferroni corrections for multiple comparisons were applied. A significance level of 0.05 was used throughout the study. Significant difference between control (C) and tested samples ( $\mathrm{PU}$ and $\mathrm{PA}): * P<0.05, * * P<0.01$.

Abbreviations: ANOVA, analysis of variance; C, control tissue culture polystyrene surface; PA, potato dearabinanated RG-l; PU, potato unmodified RG-l; RG-I, Rhamnogalacturonan-I; SEM, standard error of the mean. 

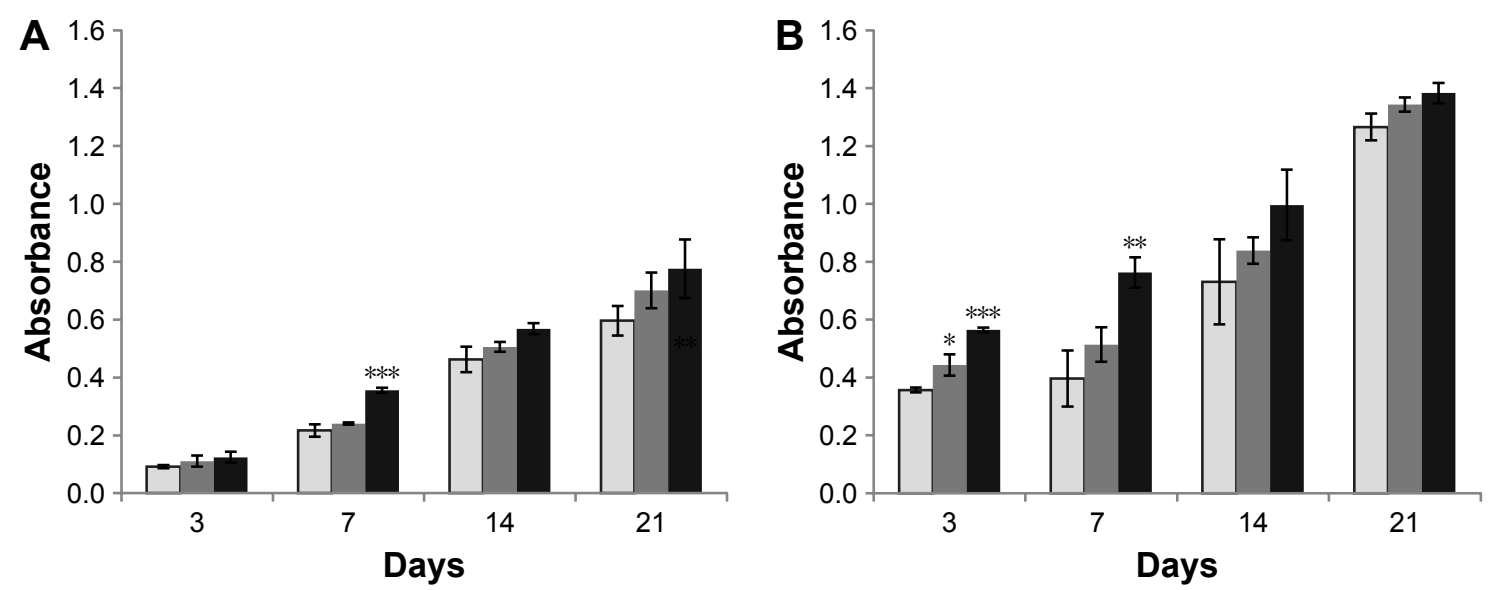

$\square \mathrm{C} \square \mathrm{PU} \square \mathrm{PA}$

Figure 3 Cell metabolic activity of B6J (A) and MC3T3-EI osteoblast cells (B) after Porphyromonas gingivalis infection measured by using water-soluble tetrazolium salt (WST-I) after 3, 7, 14, and 21 days (mean \pm SEM, $n=6$ ).

Notes: The results represent absorbance values measured at $450 \mathrm{~nm}$ against the background control wells using $650 \mathrm{~nm}$ as a reference. ANOVA tests and Bonferroni corrections for multiple comparisons were applied. A significance level of 0.05 was used throughout the study. Significant difference between control (C) and tested samples (PU and PA): $* P<0.05, * * P<0.01, * * * P<0.001$.

Abbreviations: ANOVA, analysis of variance; C, control tissue culture polystyrene surface; PA, potato dearabinanated RG-l; PU, potato unmodified RG-I; RG-I, Rhamnogalacturonan-I; SEM, standard error of the mean.

activity increases over time in infected B6J osteoblasts and MC3T3-E1 cell cultures. For B6J osteoblast cells, significantly higher cellular metabolic activity $(P<0.001)$ was observed at the PA-coated surface compared to control after 7 days, and for MC3T3-E1 osteoblast cells, significantly higher cellular metabolic activity was at PA-coated surface after $3(P<0.001)$ and 7 days $(P<0.01)$. The cellular metabolic activity at the PU-coated surface was higher in MC3T3-E1 compared to control after 3 days $(P<0.05)$.

\section{Cell mineralization}

The results of the mineralization assay (Figure 4) showed the increase of mineralized matrix over time, and the highest amount was observed after 21 days for both B6J and
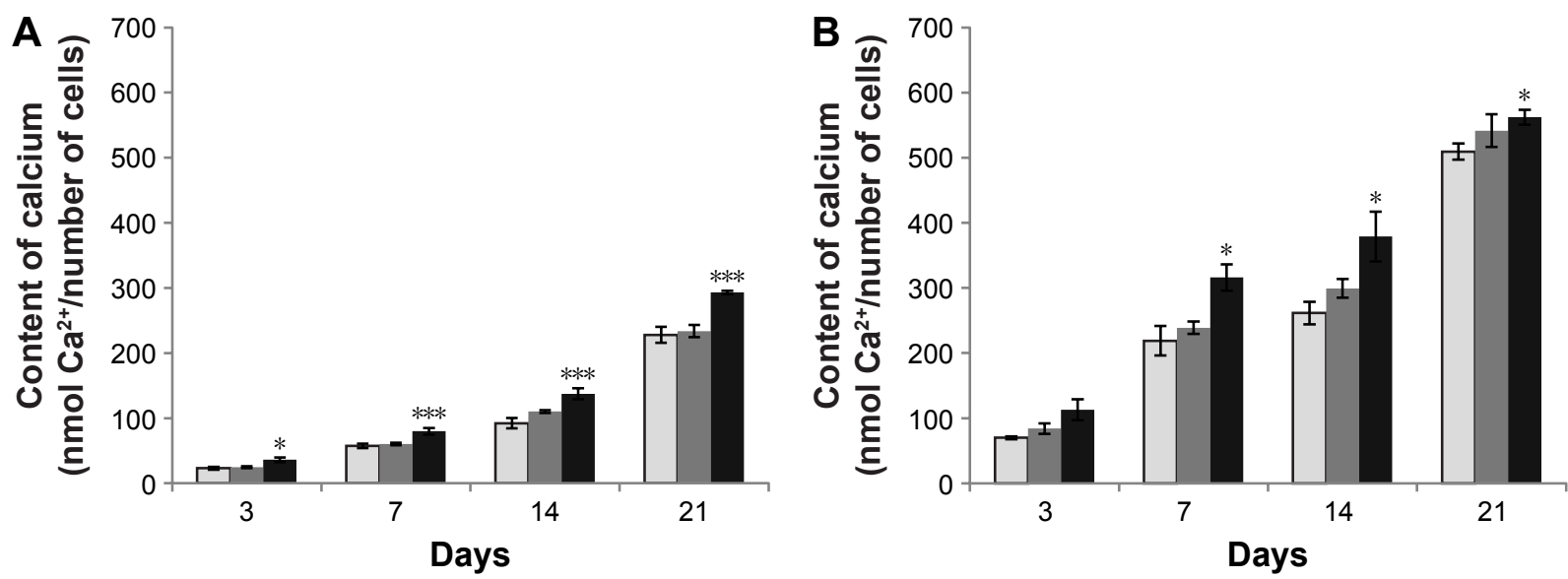

$\square \mathrm{C} \square \mathrm{PU} \square \mathrm{PA}$

Figure 4 Relative mineralization of extracellular matrix measured by an AR-S staining assay after $3,7,14$, and 21 days (mean \pm SEM, $n=6$ ) for B6 osteoblasts (A) and osteoblastic cells MC3T3-EI (B).

Notes: Results in nmol Ca ${ }^{2+}$ AR-S correspond to amount of AR-S bound to $2 \mathrm{~mol} \mathrm{Ca}{ }^{2+} / \mathrm{mol}$ of dye in solution. ANOVA tests and Bonferroni corrections for multiple comparisons were applied. A significance level of 0.05 was used throughout the study. Significant difference between control $(C)$ and tested samples $(P U$ and $P A): * P<0.05$, $* * * p<0.001$.

Abbreviations: ANOVA, analysis of variance; AR-S, Alizarin Red-S; C, control tissue culture polystyrene surface; PA, potato dearabinanated RG-I; PU, potato unmodified RG-I; RG-I, Rhamnogalacturonan-I; SEM, standard error of the mean. 
MC3T3-E1 osteoblasts. The mineralization of B6J osteoblast cells was significantly higher at PA-coated surface compared to control after $3(P<0.05), 7,14$, and 21 days $(P<0.001)$. In MC3T3-E1 cell culture, the mineralization was significantly higher at PA-coated surface compared to control after 7,14 , and 21 days $(P<0.05)$.

\section{Gene expression}

The results of the real-time PCR measurements of gene expression are shown in Figures 5 and 6. Runx2, Colla1, Bglap, Alpl, and Rankl gene expressions increased over time, from 3 to 21 days, respectively. In general, Runx2, Colla1, Bglap, and Alpl gene expressions in different endpoints $(3,7,14$, and 21 days) were highest at the PA-coated surface in infected MC3T3-E1 and B6J osteoblast cell cultures. Expression of Colla1, Bglap, and Alpl in MC3T3-E1and B6J-infected osteoblasts cell cultured at PU was lower than PA, but higher at control TCPS surface (Figure 5).

Runx2 gene expressions in infected MC3T3-E1 and B6J osteoblasts cultured on the PA-coated surfaces were significantly different compared to those at control TCPS in different time endpoints as illustrated in Figure 5. In MC3T3-E1 and B6J osteoblast cells cultured on the surface coated with PU, Runx 2 expression after 3, 7, 14, and 21 days was insignificantly upregulated compared to control TCPS. On surface coated with PA, Runx2 expression was significantly upregulated after 3,7 , and 14 days $(P \leq 0.001)$ in B6J osteoblast cell culture compared to control TCPS. The results of Runx2 gene expression in MC3T3-E1 cell culture showed that there was a significant difference between PA and control TCPS. After 3, 7, 14, and 21 days, Runx 2 expression was significantly higher $(P \leq 0.001$ for 7 days and $P \leq 0.05$ for 3 , 14 , and 21 days) in cell culture on PA than a control surface. In B6J and MC3T3-E1 osteoblast cells cultured on the PUcoated surface, Runx2 expression was higher compared to control TCPS, but no significant difference was found.

In infected B6J osteoblast cells cultured on the PA-coated surface, Collal expression was significantly upregulated compared to control TCPS after 3, $7(P<0.001)$, and 21 days $(P<0.05)$. In infected MC3T3-E1 osteoblast cells
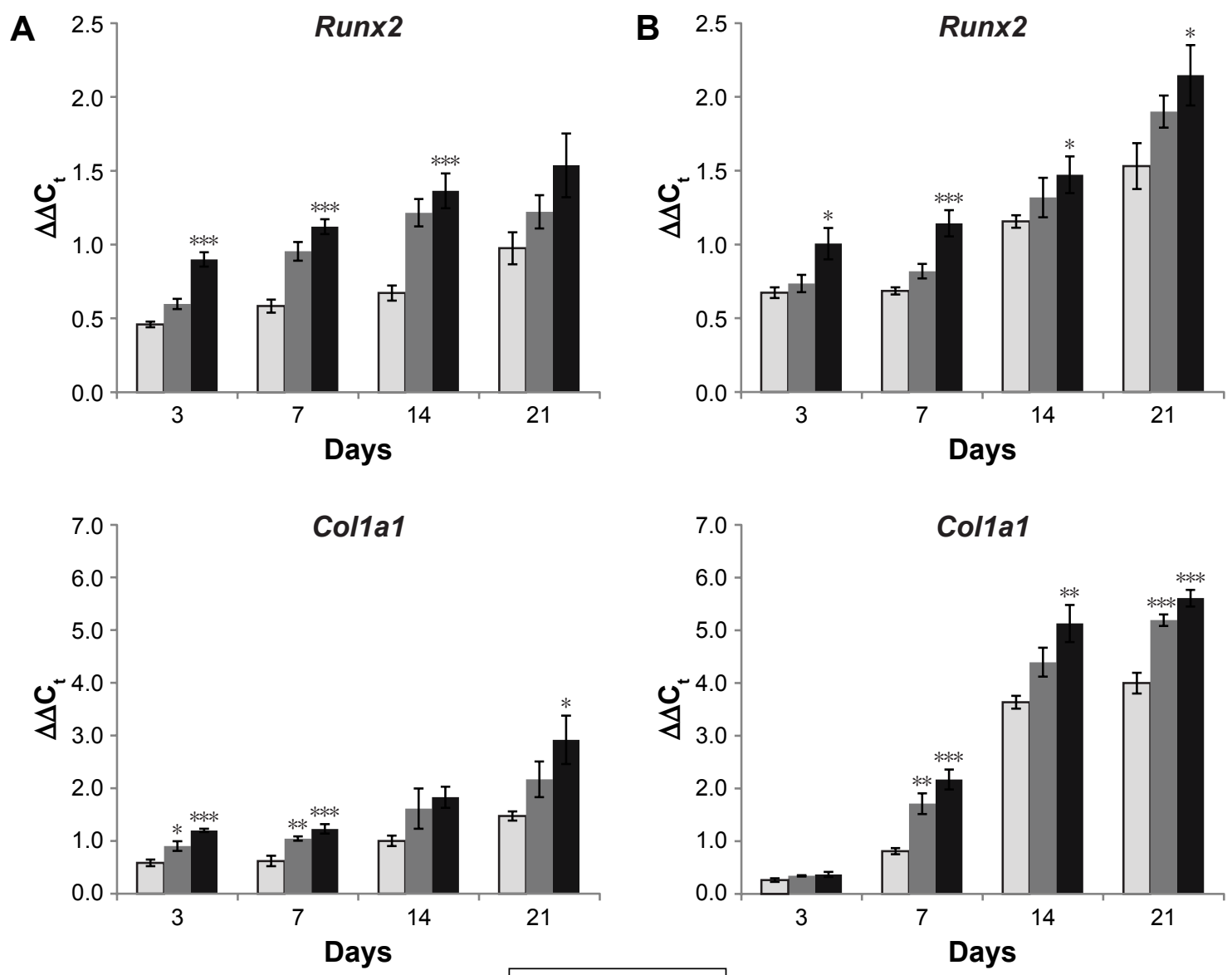

$\square C \square \mathrm{PU} \square \mathrm{PA}$

Figure 5 (Continued) 

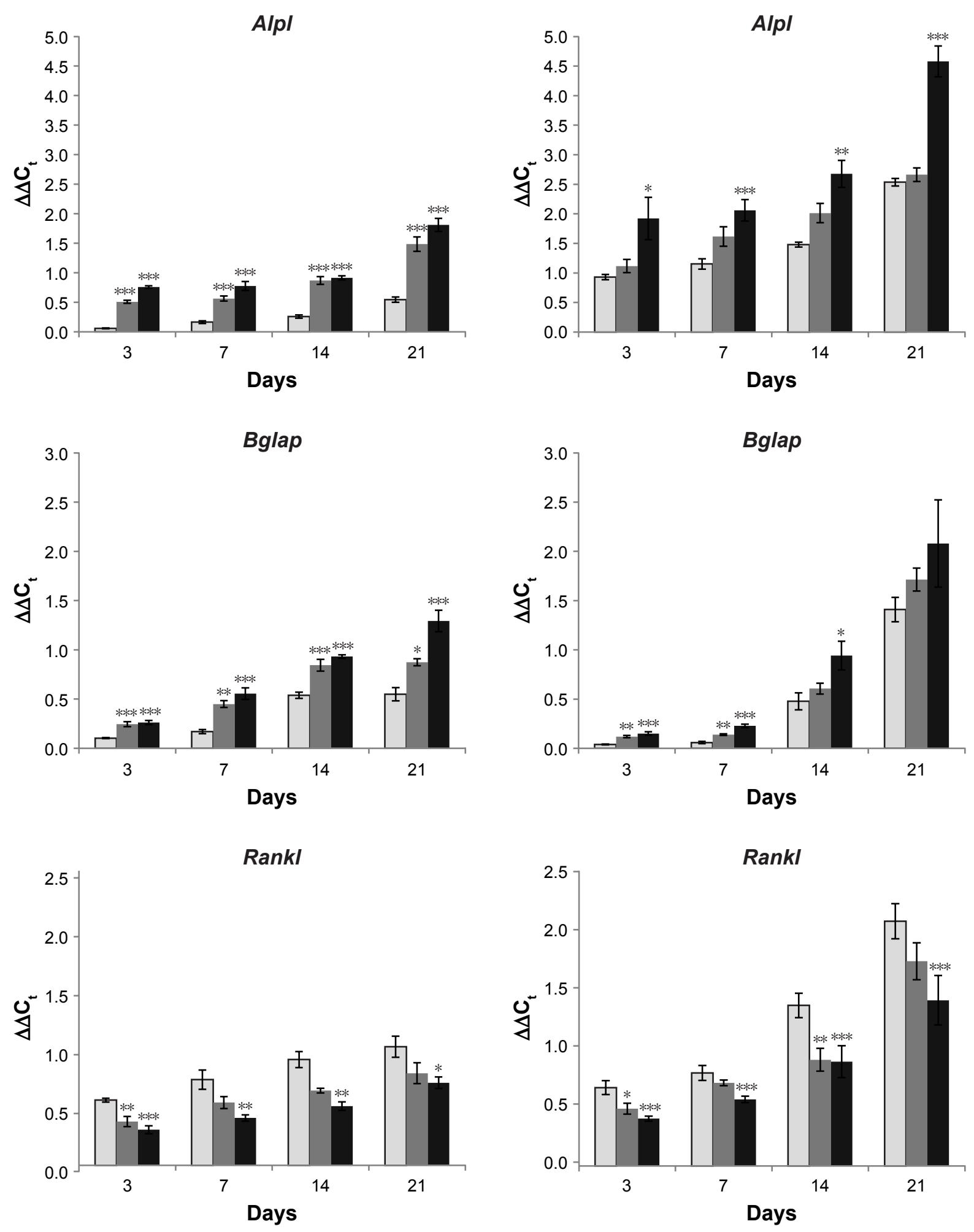

B6J

MC3T3-E1

$\square \mathrm{C} \square \mathrm{PU} \square \mathrm{PA}$

Figure 5 Real-time PCR measurements of the gene expression of Runx2, Coll al, Alpl, Bglap, and Rankl in B6] (A) and MC3T3-EI osteoblast cells (B) cultured on plates coated with PU, PA, and C after Porphyromonas gingivalis infection.

Notes: Values on the $y$-axis represent amplification efficiency $(\Delta \Delta C)$. Results are mean \pm SEM of six independent samples. ANOVA tests and Bonferroni corrections for multiple comparisons were applied. A significance level of 0.05 was used throughout the study. Significant difference between control (C) and tested samples (PU and PA): $* P<0.05, * * P<0.01$, *** $P<0.001$.

Abbreviations: ANOVA, analysis of variance; $C$, control tissue culture polystyrene surface; $\Delta \Delta C_{t}$, comparative $C_{t}$ method; PA, potato dearabinanated RG-I; PCR, polymerase chain reaction; PU, potato unmodified RG-I; RG-I, Rhamnogalacturonan-I; SEM, standard error of the mean. 

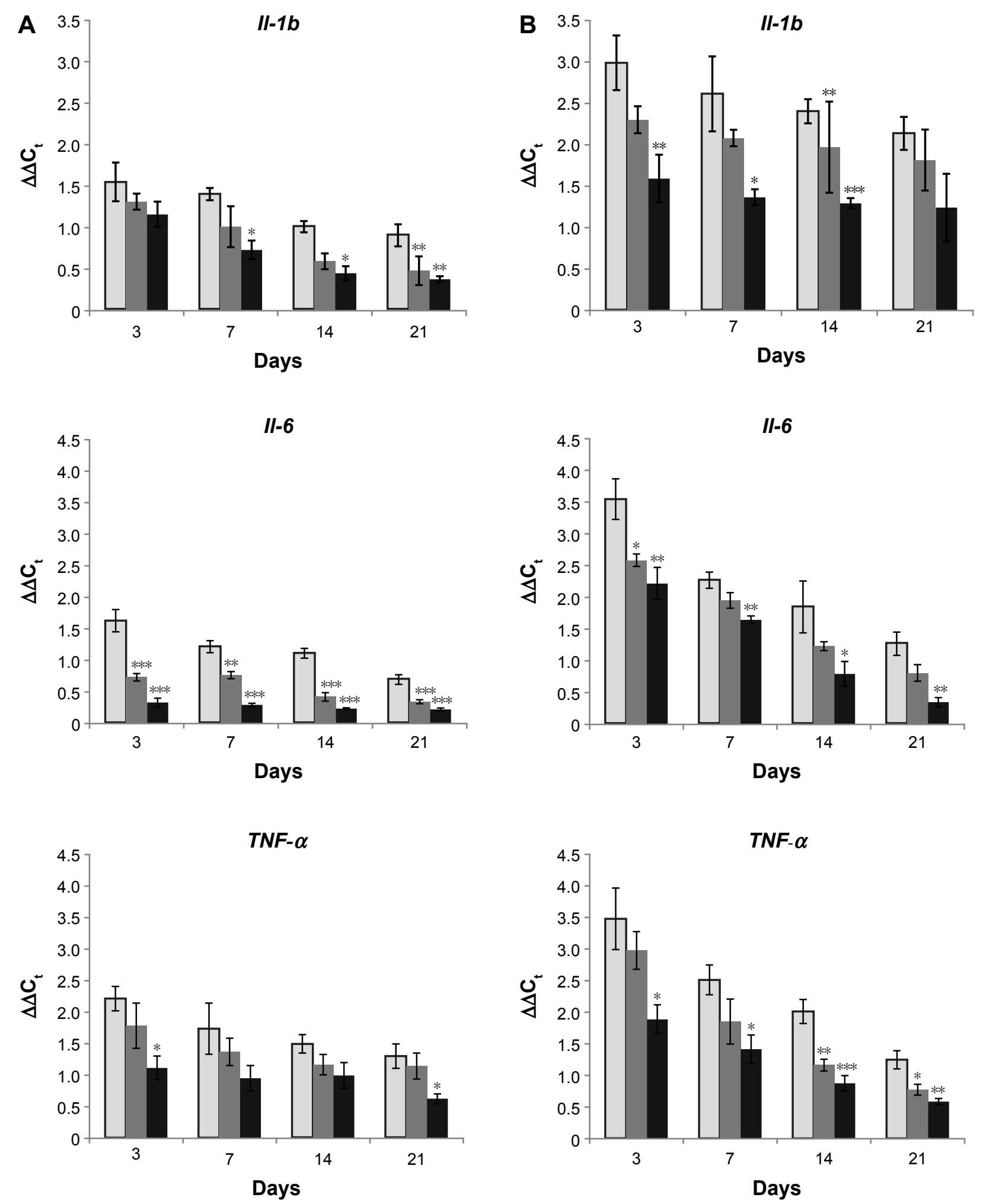

B6J

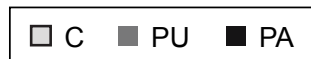

MC3T3-E1

Figure 6 Real-time PCR measurements of the gene expression of II-lb, II-6, and TNF- $\alpha$ in B6] (A) and MC3T3-El osteoblast cells (B) cultured on plates coated with PU, PA, and $C$ after Porphyromonas gingivalis infection.

Notes: Values on the $y$-axis represent amplification efficiency $\left(\Delta \Delta C_{\text {t }}\right)$. Results are mean value \pm SEM of six independent samples. ANOVA tests and Bonferroni corrections for multiple comparisons were applied. A significance level of 0.05 was used throughout the study. Significant difference between control (C) and tested samples (PU and $\mathrm{PA}): * P<0.05, * * P<0.01, * * * P<0.001$.

Abbreviations: ANOVA, analysis of variance; $C$, control tissue culture polystyrene surface; $\Delta \Delta C_{t}$, comparative $C_{t}$ method; PA, potato dearabinanated RG-I; PCR, polymerase chain reaction; PU, potato unmodified RG-I; RG-I, Rhamnogalacturonan-I; SEM, standard error of the mean. 
cultured on the surface coated with PA, Collal expression was significantly upregulated compared to control TCPS after $7(P<0.001), 14(P<0.01)$, and 21 days $(P<0.001)$. On surface coated with PU in B6J osteoblast cell cultures, Colla1 expression was significantly upregulated after $3(P<0.05)$ and $7(P<0.01)$ days compared to control TCPS. In MC3T3-E1 osteoblast cells cultured on the surface coated with PU, Collal expression was significantly higher compared to control TCPS after $7(P<0.01)$ and $21(P<0.001)$ days.

In infected B6J osteoblast cells cultured on the PAcoated surface, Alpl gene expression was significantly upregulated compared to control TCPS after 3, 7, 14, and 21 days $(P<0.001)$. In infected MC3T3-E1 osteoblast cells cultured on the surface coated with PA, Alpl gene expression was significantly upregulated compared to control TCPS after $3(P<0.05), 7(P<0.001), 14(P<0.01)$, and $21(P<0.001)$ days. On surface coated with PU in B6J osteoblast cell cultures, Alpl expression was significantly upregulated after $3,7,14$, and 21 days $(P<0.001)$ compared to control TCPS.

In infected B6J osteoblast cells cultured on the PA-coated surface, Bglap expression was significantly upregulated compared to control TCPS after 3, 7, 14, and 21 days $(P<0.001)$. In infected MC3T3-E1 osteoblast cells cultured on the surface coated with PA, Bglap expression was significantly upregulated compared to control TCPS after 3, $7(P<0.001)$, and 14 $(P<0.05)$ days. On surface coated with PU in B6J osteoblast cell cultures, Bglap expression was significantly upregulated after $3(P<0.001), 7(P<0.01), 14(P<0.001)$, and 21 $(P<0.05)$ days compared to control TCPS. In MC3T3-E1 osteoblast cells cultured on the PU-coated surface, Bglap expression was significantly higher compared to control TCPS after 3 and 7 days $(P<0.01)$.

The Rankl in infected B6J osteoblast cells cultured on the PA-coated surface was expressed significantly lower compared to control TCPS after $3(P \leq 0.001), 7,14(P \leq 0.01)$, and $21(P \leq 0.05)$ days. The Rankl in infected MC3T3-E1 cell culture was expressed significantly lower at PA-coated surface compared to control TCPS after 3, 7, 14, and 21 days $(P \leq 0.001)$. For PU-coated surface, the Rankl expression was significantly lower in B6J osteoblast cell cultures after 3 $(P \leq 0.01)$ days. In MC3T3-E1 cell cultured on the PU-coated surface, Rankl was downregulated compared to control after $3(P \leq 0.5)$ and $14(P \leq 0.01)$ days.

Expression of $I l-1 b, I l-6$, and $T N F-\alpha$ decreased over the time from 3 to 21 days, respectively. Generally, $I l-1 b$, Il-6, and TNF- $\alpha$ expressions were lower at PA-coated surface and higher at control TCPS surface in infected MC3T3-E1 and B6J osteoblast cell cultures (Figure 6).
The $I l-1 b$ in infected B6J osteoblast cells cultured on the PA-coated surface was significantly downregulated compared to control TCPS after $7,14(P \leq 0.05)$, and 21 $(P \leq 0.01)$ days. The $I l-1 b$ in infected MC3T3-E1 cell culture was expressed significantly lower at PA-coated surface compared to control TCPS after $3(P \leq 0.01), 7(P \leq 0.05)$, and 14 $(P \leq 0.001)$ days. For PU-coated surface the $I l-1 b$ expression was significantly lower in B6J osteoblast cell cultures after 21 days $(P \leq 0.01)$. In MC3T3-E1 cell cultured on the PUcoated surface $I l-1 b$ was downregulated compared to control TCPS after 14 days $(P \leq 0.01)$.

The Il-6 in infected B6J osteoblast cells cultured on the PA-coated surface was significantly downregulated compared to control TCPS after $3,7,14$, and 21 days $(P \leq 0.001)$. The Il-6 in infected MC3T3-E1 cell culture was expressed significantly lower at PA-coated surface compared to control TCPS after $3,7(P \leq 0.01), 14(P \leq 0.05)$, and $21(P \leq 0.01)$ days. For PU-coated surface the Il- 6 expression was significantly lower in B6J osteoblast cell cultures after 3, 14, 21 ( $P \leq 0.001)$, and $7(P \leq 0.01)$ days. In MC3T3-E1 cell cultured on the PU-coated surface $I l-6$ was downregulated compared to control TCPS after 3 days $(P \leq 0.5)$.

In infected B6J osteoblast cells cultured on the PA-coated surface, $T N F-\alpha$ expression was significantly downregulated compared to control TCPS after 3 and 21 days $(P \leq 0.05)$. In infected MC3T3-E1 osteoblast cells cultured on the PAcoated surface, $T N F-\alpha$ was expressed significantly lower compared to control TCPS after $3,7(P \leq 0.05), 14(P \leq 0.001)$, and $21(P<0.01)$ days. In B6J osteoblast cells cultured on the PU-coated surface, TNF- $\alpha$ expression was lower compared to control TCPS, but no significant difference was found. In MC3T3-E1 osteoblast cells cultured on the PU-coated surface, $T N F$ - $\alpha$ expression was downregulated compared to control TCPS after $14(P \leq 0.01)$ and $21(P<0.05)$ days.

\section{Discussion}

In the present study, the effect of surface nanocoating with unmodified (PU) and enzymatically modified (PA) RG-I on response of osteoblasts infected with $P$. gingivalis was assessed. Our in vitro results confirmed previous findings that the osteoblasts response to PA and PU is related to the RG-Is chemical structure. ${ }^{18,19}$ The chemical structure differences in relative amounts and lengths of side chains (galactose and arabinose) in RG-Is influenced osteoblast behavior after $P$. gingivalis infection. The RG-Is with lower content of arabinose and higher amount of galactose (PA) reduced proinflammatory response of activated osteoblasts with $P$. gingivalis and thereby stimulated the osteoblasts to produce higher amount of mineralized matrix compared to 
the unmodified RG-Is (PU). Studies have demonstrated that pectin polysaccharides isolated from other sources than PUs are potentially immunomodulatory agents, which are able to suppress the proinflammatory response of different cell types. ${ }^{14,21,22}$ However, the present data showed, for the first time, the direct anti-inflammatory effect of pectin RG-I on $P$. gingivalis-infected osteoblasts.

The $P$. gingivalis strain ATCC 33277 was applied to activate osteoblasts' inflammatory response. This strain of bacteria has been frequently used in invasion studies and has been shown to be highly invasive in culture of different cell types. ${ }^{25-31}$ In this study, osteoblast-like cells, MC3T3-E1 and primary B6J osteoblasts from mice were used to evaluate the capacity of modified (PA) and unmodified (PU) RG-Is to inhibit the gene expression of inflammatory mediators and to improve mineralized matrix formation following infection. According to our results, RG-Is influence osteoblast proliferation after infection with $P$. gingivalis. We found that there were more proliferating cells in different time points on the surfaces coated with PA compared to control TCPS surfaces, which indicates the influence of RG-Is on osteoblasts' activation. Similar results have been reported by Gallet et $\mathrm{al}^{32}$ with murine macrophage cell line J774.2 cultured on pectin MHR- $\alpha$ (modified hairy regions) from apple in the presence of bacterial LPSs. The MHR- $\alpha$ nanocoating inhibits the LPS-induced activation of macrophages.

Our study showed that RG-I pectin, especially PA, significantly inhibited the decrease induced by $P$. gingivalis in proliferation of osteoblasts compared to control surface without pectins. This finding is important due to the fact that $P$. gingivalis has a direct effect on bone resorption through inhibition of osteoblast proliferation. ${ }^{10}$ Bone resorption is mediated by proinflammatory cytokines, which are produced and secreted by osteoblasts in response to bacterial infection. Inflammatory mediators, such as $I l-1 b, I l-6$, and $T N F-\alpha$, have been reported to inhibit osteoblastic differentiation and induce activation of bone-resorbing osteoclasts. ${ }^{33}$

In our study, the osteoblast differentiation, mineralized matrix formation, and proinflammatory cytokines production were observed by measuring gene expression levels in real-time PCR, supplemented with a biochemical mineralization assay based on Alizarin Red staining and EC calcium deposition at different time points $(3,7,14$, and 21 days $)$ to identify the behavior of $P$. gingivalis-activated cells during the whole osteoblast lineage. The selection of time points is in agreement with other studies. ${ }^{33}$ According to our results, the amount of EC calcium deposition (Alizarin Red staining) after infection was higher on surfaces coated with PA. However, the Alizarin Red staining is used as a quality rather than a quantity biochemical mineralization assay; ${ }^{34}$ therefore, gene expression was included in our study to control mineralization on the molecular level. The results of gene expression indicated that RG-I pectins prevent the decrease in osteoblast differentiation and matrix mineralization in response to $P$. gingivalis. The previous reports showed that bacterial virulence factors such as LPSs potently suppressed osteoblast differentiation through inhibition of the Runx2 gene expression. ${ }^{33}$ Our present data showed that PA increased the expression of the Runx2 gene in both MC3T3-E1- and primary B6J-infected osteoblasts after 3, 7, 14, and 21 days compared to controls. According to these observations, RG-I with low content of arabinose and high content of galactose stimulates osteoblast activity after bacterial infection in the early stage of differentiation. This finding is important as Runx2 is considered to be essential for the promotion of mesenchymal cells into osteoblast progenitors and upregulation of osteogenic differentiation markers such as alkaline phosphate, osteopontin, bone sialoprotein, and osteocalcin. ${ }^{35}$ Furthermore, we found that RG-I-coated surfaces increased the expression of genes related to matrix formation (Collal), matrix maturation $(\mathrm{Alpl})$, and matrix mineralization (Bglap) in both infected MC3T3-E1 and B6J osteoblasts at different time points, which indicates that the nanocoating might stimulate bone healing and osseointegration in vivo. Our results show that RG-I pectin significantly inhibited the decrease in osteoblastic maturation, differentiation, and mineral matrix formation following $P$. gingivalis infection. $P$. gingivalis is a potent stimulator of inflammatory mediators such as $I l-1 b, I l-6$, and TNF- $\alpha$, which induces bone resorption through activation of osteoclasts. ${ }^{34,36-39}$ Therefore, the level of cytokines $I l-1 b, I l-6$, and $T N F-\alpha$ gene expression was assessed in MC3T3-E1- and B6J-infected osteoblasts cultured on PU and PA pectin substrates. Our results showed a decrease in levels of cytokines gene expression in both cell types grown on the surface coated with RG-Is compared to control at different time points. This indicated that RG-Is, especially pectin substratum with lower arabinose content, significantly inhibit the expression of inflammatory mediators in osteoblasts infected with $P$. gingivalis. This is in line with a study by Gallet et $\mathrm{al}^{32}$ using a murine macrophage cell line J774.2 cultured on pectin MHR- $\alpha$ from apple and stimulated by bacterial LPSs. The MHR- $\alpha$ substratum significantly inhibits the secretion of proinflammatory TNF- $\alpha$ mediator and generation of nitrous oxide by LPS-activated macrophages. Therefore, RG-I nanocoatings on surfaces seem to reduce cytokine-mediated bone destruction following bacterial infection. The Rankl has been established as a key mediator of inflammatory bone loss. ${ }^{37} \mathrm{We}$ found that the 
level of Rankl expression in MC3T3-E1- and B6J-infected osteoblasts cultured on the PA- and PU-coated surfaces was lower than control surfaces at different time points, indicating reduced osteoclastogenesis, which subsequently could lead to reduced bone resorption in response to $P$. gingivalis infection. Taken as a whole, our results demonstrate that RG-Is may affect osteoblast behavior following inflammatory process, enhancing cell proliferation, differentiation, and mineralization of bone matrix, but also downregulating $I l-1 b$, Il-6, TNF- $\alpha$, and Rankl expressions in osteoblasts which would lead to reduced osteoclast formation..$^{34,36-39}$ The in vitro results obtained from the current research suggest that sugar composition of RG-Is modulates the cell response to bacterial infection. The nanocoating with PA, with higher amount of galactose compared to PU, influenced higher proliferation (BrdU), mineralized matrix formation (AR-S), cell metabolic activity (WST-1), gene expressions of Runx2, Colla1, Alpl, and Bglap, and also lower expression levels of $I l-1 b, I l-6$, $T N F-\alpha$, and Rankl. Our findings support the results from earlier studies indicating that surfaces with short arabinian side chains and high amount of galactose enhance osteoblast cells' spreading and growth, in contrast to the RG-Is with high amounts of arabinian, which lead to aggregation and decreased proliferation. . $^{12,13,40}$

Nevertheless, in cell metabolic activity and proliferation, the significant differences between RG-I surfaces and control surfaces were not observed in each selected time point. ${ }^{18,19}$

The lack of significant difference can be explained by the fact that the RG-I in this study was adherently coated on the surface, not covalently. However, the most important part of the osseointegration process is the formation of the ECM by osteoblasts and the following mineralization, which in our studies was investigated with a cell mineralization assay and gene expression levels using real-time PCR.

Our findings suggest that RG-I structure stimulates proliferation, metabolic activity, and mineralization of osteoblasts confirmed by a variety of gene expressions. The results indicate that linear 1,4-linked galactans have the capacity to limit inflammation and promote bone healing following bacterial infection. It has previously been reported that galectin-3 present in the membrane of osteoblastic cells not only binds specifically to galactose residues ${ }^{41,42}$ but also interacts strongly with pathogenic bacteria via bacterial LPSs. ${ }^{43,44}$ Therefore, it can be speculated that anti-inflammatory effect of RG-I pectin is mediated through the galectin-3 receptor. However, potential relationships as well as molecular mechanism of interactions between RG-I structure and receptors in osteoblastic cells under $P$. gingivalis infection need to be investigated.

\section{Conclusion}

The plant-derived polysaccharides, especially RG-I with high content of galactose, influenced $P$. gingivalis-infected osteoblast morphology, proliferation, and mineralization. Our results indicate for the first time the capacity of RG-I pectins to inhibit inflammatory osteoblast response following bacterial infection through downregulation of $I l-1 b$, Il-6, and $T N F-\alpha$ gene expressions. The present results open new direction in the development of innovative pectin surface nanocoatings for biomaterial applications in order to reduce inflammatory response of osteoblasts and improve bone healing in immunocompromised patients with high risk for bacterial infection. The possible anti-inflammatory effects of RG-I pectins should be investigated with further in vitro and in vivo studies.

\section{Acknowledgments}

The project was supported by Marie Skłodowska-Curie grant (FP-7 \#290246). The authors thank RAPID (Rheumatoid Arthritis and Periodontal Inflammatory Disease) research group for their support in performing experiments and Bodil Jørgensen and Pete Ulvskov from University of Copenhagen for providing RG-Is. The abstract of this paper was presented at the International Symposium Osteology Monaco 2016 as a poster presentation with interim findings.

\section{Disclosure}

The authors report no conflicts of interest in this work.

\section{References}

1. Detert J, Pischon N, Burmester GR, Buttgereit F. The association between rheumatoid arthritis and periodontal disease. Arthritis Res Ther. 2010;12(5):218.

2. Dissick A, Redman RS, Jones M, et al. Association of periodontitis with rheumatoid arthritis: a pilot study. J Periodontol. 2010;81(2):223-230.

3. Koziel J, Mydel P, Potempa J. The link between periodontal disease and rheumatoid arthritis: an updated review. Curr Rheumatol Rep. 2014; 16(3):408.

4. Bostanci N, Belibasakis GN. Porphyromonas gingivalis: an invasive and evasive opportunistic oral pathogen. FEMS Microbiol Lett. 2012; 333(1):1-9.

5. Mikuls TR, Payne JB, Reinhardt RA, et al. Antibody responses to Porphyromonas gingivalis ( $P$. gingivalis) in subjects with rheumatoid arthritis and periodontitis. Int Immunopharmacol. 2009;9(1):38-42.

6. Araujo VM, Melo IM, Lima V. Relationship between periodontitis and rheumatoid arthritis: review of the literature. Mediators Inflamm. 2015;2015:259074.

7. Papadopoulos G, Weinberg EO, Massari P, et al. Macrophagespecific TLR2 signaling mediates pathogen-induced TNF-dependent inflammatory oral bone loss. J Immunol. 2013;190(3):1148-1157.

8. Verdugo F, Castillo A, Simonian K, et al. Periodontopathogen and Epstein-Barr virus contamination affects transplanted bone volume in sinus augmentation. J Periodontol. 2012;83(2):162-173.

9. Verdugo F, Castillo A, Moragues MD, Ponton J. Bone microbial contamination influences autogenous grafting in sinus augmentation. J Periodontol. 2009;80(8):1355-1364. 
10. Le XK, Laflamme C, Rouabhia M. Porphyromonas gingivalis decreases osteoblast proliferation through IL-6-RANKL/OPG and MMP-9/TIMPs pathways. Indian J Dent Res. 2009;20(2):141-149.

11. Kokkonen H, Cassinelli C, Verhoef R, Morra M, Schols HA, Tuukkanen J. Differentiation of osteoblasts on pectin-coated titanium. Biomacromolecules. 2008;9(9):2369-2376.

12. Kokkonen HE, Ilvesaro JM, Morra M, Schols HA, Tuukkanen J. Effect of modified pectin molecules on the growth of bone cells. Biomacromolecules. 2007;8(2):509-515.

13. Morra M, Cassinelli C, Cascardo G, et al. Effects on interfacial properties and cell adhesion of surface modification by pectic hairy regions. Biomacromolecules. 2004;5(6):2094-2104.

14. Bussy C, Verhoef R, Haeger A, et al. Modulating in vitro bone cell and macrophage behavior by immobilized enzymatically tailored pectins. J Biomed Mater Res A. 2008;86(3):597-606.

15. Nagel MD, Verhoef R, Schols H, et al. Enzymatically-tailored pectins differentially influence the morphology, adhesion, cell cycle progression and survival of fibroblasts. Biochim Biophys Acta. 2008;1780(7-8): 995-1003.

16. Gurzawska K, Svava R, Yihua Y, et al. Osteoblastic response to pectin nanocoating on titanium surfaces. Mater Sci Eng CMater Biol Appl. 2014; 43:117-125.

17. Gurzawska K, Svava R, Jørgensen NR, Gotfredsen K. Nanocoating of titanium implant surfaces with organic molecules. Polysaccharides including glycosaminoglycans. J Biomed Nanotechnol. 2012;8(6): 1012-1024.

18. Gurzawska K, Svava R, Syberg S, et al. Effect of nanocoating with rhamnogalacturonan-I on surface properties and osteoblasts response. J Biomed Mater Res A. 2012;100(3):654-664.

19. Svava R, Gurzawska K, Yihau Y, et al. The structurally effect of surface coated rhamnogalacturonan I on response of the osteoblast-like cell line SaOS-2. J Biomed Mater Res A. 2013;102(6):1961-1971.

20. Inngjerdingen KT, Patel TR, Chen X, et al. Immunological and structural properties of a pectic polymer from Glinus oppositifolius. Glycobiology. 2007;17(12):1299-1310.

21. Popov SV, Ovodova RG, Popova GY, Nikitina IR, Ovodov YS. Adhesion of human neutrophils to fibronectin is inhibited by comaruman, pectin of marsh cinquefoil Comarum palustre L., and by its fragments. Biochemistry (Mosc). 2005;70(1):108-112.

22. Popov SV, Popova GY, Nikolaeva SY, Golovchenko VV, Ovodova RG. Immunostimulating activity of pectic polysaccharide from Bergenia crassifolia (L.) Fritsch. Phytother Res. 2005;19(12):1052-1056.

23. Gurzawska KA. Nanocoating of Implant Surfaces with Pectin Rhamnogalacturonan-ls, Review and In Vitro Studies [PhD thesis]. 1st. ed. Kbh.: Faculty of Health and Medical Sciences, University of Copenhagen; 2013.

24. Dittmann C, Doueiri S, Kluge R, Dommisch H, Gaber T, Pischon N. Porphyromonas gingivalis suppresses differentiation and increases apoptosis of osteoblasts from New Zealand Obese Mice. J Periodontol. 2015;86(9):1095-1102.

25. Basler T, Holtmann H, Abel J, et al. Reduced transcript stabilization restricts TNF-alpha expression in RAW264.7 macrophages infected with pathogenic mycobacteria: evidence for an involvement of lipomannan. J Leukoc Biol. 2010;87(1):173-183.
26. Hajishengallis E, Hajishengallis G. Neutrophil homeostasis and periodontal health in children and adults. J Dental Res. 2014;93(3):231-237.

27. Hajishengallis G. The inflammophilic character of the periodontitisassociated microbiota. Mol Oral Microbiol. 2014;29(6):248-257.

28. Urnowey S, Ansai T, Bitko V, Nakayama K, Takehara T, Barik S. Temporal activation of anti- and pro-apoptotic factors in human gingival fibroblasts infected with the periodontal pathogen, Porphyromonas gingivalis: potential role of bacterial proteases in host signalling. $B M C$ Microbiol. 2006;6:26.

29. Walter C, Zahlten J, Schmeck B, et al. Porphyromonas gingivalis strain-dependent activation of human endothelial cells. Infect Immun. 2004;72(10):5910-5918.

30. White PC, Chicca IJ, Cooper PR, Milward MR, Chapple IL. Neutrophil extracellular traps in periodontitis: a web of intrigue. J Dent Res. 2016;95(1):26-34.

31. Pischon N, Rohner E, Hocke A, et al. Effects of Porphyromonas gingivalis on cell cycle progression and apoptosis of primary human chondrocytes. Ann Rheum Dis. 2009;68(12):1902-1907.

32. Gallet M, Vayssade M, Morra M, et al. Inhibition of LPS-induced proinflammatory responses of J774.2 macrophages by immobilized enzymatically tailored pectins. Acta Biomater. 2009;5(7):2618-2622.

33. Bandow K, Maeda A, Kakimoto K, et al. Molecular mechanisms of the inhibitory effect of lipopolysaccharide (LPS) on osteoblast differentiation. Biochem Biophys Res Commun. 2010;402(4):755-761.

34. Kato H, Taguchi Y, Tominaga K, Umeda M, Tanaka A. Porphyromonas gingivalis LPS inhibits osteoblastic differentiation and promotes pro-inflammatory cytokine production in human periodontal ligament stem cells. Arch Oral Biol. 2014;59(2):167-175.

35. Komori T. Regulation of bone development and extracellular matrix protein genes by RUNX2. Cell Tissue Res. 2010;339(1):189-195.

36. Abu-Amer Y, Erdmann J, Alexopoulou L, Kollias G, Ross FP, Teitelbaum SL. Tumor necrosis factor receptors types 1 and 2 differentially regulate osteoclastogenesis. J Biol Chem. 2000;275(35):27307-27310.

37. Hienz SA, Paliwal S, Ivanovski S. Mechanisms of bone resorption in periodontitis. J Immunol Res. 2015;2015:615486.

38. Ishimi Y, Miyaura C, Jin CH, et al. IL-6 is produced by osteoblasts and induces bone resorption. J Immunol. 1990;145(10):3297-3303.

39. Kadono H, Kido J, Kataoka M, Yamauchi N, Nagata T. Inhibition of osteoblastic cell differentiation by lipopolysaccharide extract from Porphyromonas gingivalis. Infect Immun. 1999;67(6):2841-2846.

40. Kokkonen H, Niiranen H, Schols HA, Morra M, Stenback F, Tuukkanen J. Pectin-coated titanium implants are well-tolerated in vivo. J Biomed Mater Res A. 2010;93(4):1404-1409.

41. Gao X, Zhi Y, Sun L, et al. The inhibitory effects of a rhamnogalacturonan I (RG-I) domain from ginseng pectin on galectin-3 and its structureactivity relationship. J Biol Chem. 2013;288(47):33953-33965.

42. Gunning AP, Bongaerts RJ, Morris VJ. Recognition of galactan components of pectin by galectin-3. FASEB J. 2009;23(2):415-424.

43. Kavanaugh D, Kane M, Joshi L, Hickey RM. Detection of galectin-3 interaction with commensal bacteria. Appl Environ Microbiol. 2013; 79(11):3507-3510.

44. Mey A, Leffler H, Hmama Z, Normier G, Revillard JP. The animal lectin galectin-3 interacts with bacterial lipopolysaccharides via two independent sites. J Immunol. 1996;156(4):1572-1577.

International Journal of Nanomedicine

\section{Publish your work in this journal}

The International Journal of Nanomedicine is an international, peerreviewed journal focusing on the application of nanotechnology in diagnostics, therapeutics, and drug delivery systems throughout the biomedical field. This journal is indexed on PubMed Central, MedLine, CAS, SciSearch $\AA$, Current Contents ${ }^{\circledR} /$ Clinical Medicine,

Journal Citation Reports/Science Edition, EMBase, Scopus and the Elsevier Bibliographic databases. The manuscript management system is completely online and includes a very quick and fair peer-review system, which is all easy to use. Visit http://www.dovepress.com/ testimonials.php to read real quotes from published authors.

\footnotetext{
Submit your manuscript here: http://www.dovepress.com/international-journal-of-nanomedicine-journal
} 